www.jmscr.igmpublication.org

Impact Factor (SJIF): 6.379

Index Copernicus Value: 79.54

ISSN (e)-2347-176x ISSN (p) 2455-0450

crossrefDOI: https://dx.doi.org/10.18535/jmscr/v6i9.131

Journal Of Medical Science And Clinical Research

IGM Publication

An Official Publication of IGM Publication

\title{
A Study on Incidence and Etiology of Hyponatremia in Hospitalised Elderly Patients Admitted in RIMS
}

\author{
Authors \\ Lokesh $\mathbf{N ~ K}^{1^{*}}$, Yamunaraj S D \\ ${ }^{1}$ Assistant Professor Dept of General Medicine MIMS Mandya Karnataka India \\ ${ }^{2} \mathrm{CMO}$, Dept of Casualty, MIMS Mandya Karnataka India \\ *Corresponding Author \\ Lokesh N K \\ Assistant Professor Dept of General Medicine MIMS Mandya 571401 Karnataka India \\ Email:lahari2k253@gmail.com
}

\begin{abstract}
Background: Hyponatremia is one of the commonest electrolyte abnormality in clinical practice and most common cause for hospital admission among elderly patients. Causing significant mortality and morbidity. Early detection and treatment may significantly decrease mortality.

Aim: To know the incidence and etiology of hyponatremia

Materials and Methods: This was prospective observational study done between October 2011 to October 2012 at Rajendra Institute of Medical Sciences, Dept of General Medicine, Ranchi. All patients with more than 60 yrs of age with atleast two serum values less than $130 \mathrm{mmol} / \mathrm{L}$ were included.

Results: Total no of patients admitted was 2100 and serum Sodium done for 2000 patients. Incidence of hyponatremia was $18.9 \%$ and severe hyponatremia was 5\%.Most common age group affected with hyponatremia was 61-70 yrs (44\%). Most common symptom was nausea, vomiting, seizure and altered sensorium. Most common etiology for hyponatremia was SIADH (28\%) and Diuretics was second commonest cause (15\%).

Conclusion: Symptamatic hyponatremia was more common among hospitalised elderly patients, SIADH and Diuretics was most common cause for hyponatremia. Mortality was about 10\%, was mainly due to underlying primary disease. Most of symptoms of hyponatremia were relievd following treatment.

Keywords: Hyponatremia, SIADH, Diuretics, Vomiting, Seizures.
\end{abstract}

\section{Introduction}

Disorders of serum $\mathrm{Na}+$ concentration are caused by abnormalities in water homeostasis, leading to changes in the relative ratio of $\mathrm{Na}+$ to body water. Water intake and circulating AVP constitute the two key effectors in the defense of serum osmolality; defects in one or both of these two defense mechanisms cause most cases of hyponatremia and hypernatremia. Hyponatremia, which is defined as a plasma $\mathrm{Na}+$ concentration $<135 \mathrm{mM}$, is a very common disorder, occurring in up to $22 \%$ of hospitalized patients. This disorder is almost always the result of an increase in circulating AVP and/or increased renal sensitivity to AVP, combined with an intake of free water; a notable exception is hyponatremia 
due to low solute intake. The underlying pathophysiology for the exaggerated or "in appropriate" AVP response differs in patients with hyponatremia as a function of their ECFV. Hyponatremia is thus subdivided diagnostically into three groups, depending on clinical history and volume status, i.e., "hypovolemic," "euvolemic," and "hypervolemic".

Hyponatremia is one of the common electrolyte disorder, contributing emergency hospital admission, causing significant mortality and morbidity. Incidence of Hyponatremia in hospitalised patients range from $15-30 \%$, it can reach up to $40-50 \%$ in elderly patients ${ }^{12}$.

High incidence of Hyponatremia in elderly patients due to multiple factors, intake of multiple drugs like diuretics, Psychiatric drugs like SSRI, comorbid condition like IHD, Renal disease and impaired thirst mechamism and problem in age related cognition ${ }^{14}$.

Symptoms of Hyponatremia depends upon onset and severity. Usually chronic Hyponatremia are asympatmatic. Acute and severe Hyponatremia mostly symptomatic ${ }^{5}$.

Common symptoms of hyponatremia include nausea, vomiting, giddiness, seizure episodes and sometimes come and death ${ }^{6}$.

On the basis of osmolarity Hyponatremia can be classified into Hypertonic, Isotonic and Hypotonic Hyponatremia respectively.

Hypotonic Hyponatremia further classified in to hypovolumic, Euvolumic, Hepervolumic Hyponatremia respectively. Euvolemic Hyponatremia was most common type of Hyponatremia in elderly patients. Most common etiology for Euvolumic Hyponatremia was SIADH $^{6}$.

\section{Aims and Objectives}

To know the incidence and etiological cause for hyponatremia.

\section{Materials and Methods}

This was prospective cross sectional observational study conducted over a period of one year from October 2011 to October 2012 at RIMS Ranchi.

\section{Inclusion criteria}

All patients $>60$ years with atleast two Serum sodium values $<130 \mathrm{Mmol} / \mathrm{L}$

\section{Exclusion criteria}

Patients with age $<60$ years

Patients with Pseudohyponatremia

The lab values of serum Sodium of all patients from October 2011 to October 2o12 was studied from which incidence of Hyponatremia was calculated. Out of this Hyponatremic patients, a sample size of 100 patients were randomly selected by simple random sampling.

In the hospital all the patients admitted to wards and Micu during that period, as routine blood samples were taken and serum electrolytes were done in central biochemistry laboratory. The records were followed up for patients with hyponatremia and values repeated once for confirmation.

A standard proforma was used to record detailed history and clinical examination findings. The probable cause was diagnosed and outcome of hospitalization was recorded.

All the date entered to SPSS 22 version. Hyponatremia incidence in the hospitalized elderly patients was calculated. The relationships between hyponatremia severity and age groups, sex, duration of hospital stay and outcome were studied using the chi-square, independent student's T test and Mann Whitney U tests. The results were evaluated by hazard ratio and $95 \%$ confidence interval. In these analyses, $\mathrm{p}$ values $<0.05$ were considered statistically significant.

\section{Results}

The total number of patients admitted to Medicine dept was 2100 and serum Sodium was done for 2000 patients. The number of patients with serum Sodium less than $130 \mathrm{mmol} / \mathrm{l}$ was about 378 patients. Incidence of Hyponatremia was $18.9 \%$. 
Incidencde of Severe Hyponatremia was $5 \%$. Incidence of Hyponatremia in Micu was 36\%.

Most coomon age group affected was $61-70$ years (54\%), followed by $71-80$ years $(30 \%)$ Total number of male patients were $57(57 \%)$ and female patients were 43(43\%).

Common chronic disease associated with hyponatremia patients was HTN (58\%), DM $(50 \%)$, Cardiac disease (31\%), Respiratory disease $(16 \%)$ and CKD (10\%).

Out of 100 patients 62(62\%) were euvolimic,19 (19\%) were hypervolumic, 19 (19\%) were hypovolemic. The mean intial serum Sodium was $118 \mathrm{mmol} / \mathrm{l}$

Most common cause for Hyponatremia was SIADH (28\%), Diuretics (15\%), Dehydration (12\%). Out of 100 patients 90 patients improved (90\%), 2 patients gone DAMA and $8(8 \%)$ patients died.

\section{Discussion}

Incidence of hyponatremiaia common in elderly patients and it can cause significant mortality if not treated early. Incidence of hyponatremia in our study was $18.9 \%$,incidence of severe hyponatremia was $5 \%$ and incidence of hyponatremia in MICU patients was $36 \%$, may be because of comorbid other conditions like cardiac and renal disease. Study done by Nuket Bayram Kayar et al showed incidence of hyponatremia was $18 \%$.Study done by Waikar et al showed $14.5 \%$ incidence. (Table-1).Study done by Sandar Win et al showed incidence severe hyponatremia was $4.8 \%$.

Table 1 Comparison of incidence with different studies

\begin{tabular}{|l|c|}
\hline \multicolumn{1}{|c|}{ Studies } & Incidence (\%) \\
\hline Present study & $18.9 \%$ \\
\hline Nuket Bayram Kayar et al $^{6}$ & $18 \%$ \\
\hline Waikar et al $^{14}$ & $14.5 \%$ \\
\hline Gosch et al $^{15}$ & $16.7 \%$ \\
\hline
\end{tabular}

Most common age group was 61-65(30\%) years followed by 66-70 years (26\%).More common in males (57\%), compared to females (43\%). Study done by Soni Kumar et al showed most common age group was $61-65(31 \%)$ and $56 \%$ were males and $44 \%$ were females. In our study mean age was 68.62 years. Most common symptoms in our study was nausea and vomiting (67\%) . (Table-2)

Table 2 Comparison of clinical profile with different studies

\begin{tabular}{|l|c|c|}
\hline Clinical profile & Present study & Sonikumar et $\mathrm{al}^{5}$ \\
\hline 61-65 years & $30 \%$ & $31 \%$ \\
\hline $66-70$ years & $26 \%$ & $22 \%$ \\
\hline Males & $57 \%$ & $56 \%$ \\
\hline Females & $43 \%$ & $44 \%$ \\
\hline Mean age & 68.62 years & 71.26 years \\
\hline Symptoms & $\begin{array}{c}\text { Nausea, } \\
\text { vomiting }\end{array}$ & Nausea, vomiting \\
\hline
\end{tabular}

In our study most patients had chronic disease like Diabetes mellitus (50\%), Hypertension (58\%), Cardiac disease $(31 \%)$ and Respiratory disease. This may be reason for Higher incidence of hyponatremia in elderly patients. (Table-3)

Table 3 Comparison of frequency of pre existing disease with other studies

\begin{tabular}{|c|c|c|}
\hline $\begin{array}{ll}\text { Pre } & \text { existing } \\
\text { disease } & \\
\end{array}$ & $\begin{array}{c}\text { Present } \\
\text { study }(\%)\end{array}$ & $\begin{array}{c}\text { Shanmugasundara } \\
\text { mRajamani }^{4}(\%)\end{array}$ \\
\hline $\mathrm{DM}$ & $50 \%$ & $63 \%$ \\
\hline HTN & $58 \%$ & $44 \%$ \\
\hline CHD & $31 \%$ & $24 \%$ \\
\hline CKD & $10 \%$ & $9 \%$ \\
\hline COPD & $16 \%$ & $19 \%$ \\
\hline
\end{tabular}

In our study $29 \%$ patients taking diuretics for other pre existing disease loke HTN and CHD. This was the common reason for hyponatremia in elderly patients. In our study $29 \%$ were mild hyponatremic, $56 \%$ were moderate hyponatremic and 5\% were severe hyponatremic. All the patients with severe hyponatremia were symptomatic. As the severity of hyponatremia increases it causes more symptoms. (Table-4)

According to hydration status, $62 \%$ patients were Euvolumic,19\% were Hypervolumic and 19\% were Hypovolumic. Most common etiology was SIADH, followed by drugs like Diuretics. Mortality was about 8\%.(Table-5) 
Table 4 Comparison of Hypotonic hyponatremia with other studies

\begin{tabular}{|l|c|c|}
\hline Volume status & $\begin{array}{c}\text { Present } \\
\text { study(\%) }\end{array}$ & $\begin{array}{c}\text { Shanmugasundaram } \\
\text { Rajamani }(\%)\end{array}$ \\
\hline Euvolumic & $62 \%$ & $59.5 \%$ \\
\hline Hypervolumic & $19 \%$ & $23.4 \%$ \\
\hline Hypovolumic & $19 \%$ & $17 \%$ \\
\hline
\end{tabular}

Table 5 Comparison of etiologies with other studies

\begin{tabular}{|l|c|c|}
\hline Etiology & $\begin{array}{c}\text { Present } \\
\text { study (\%) }\end{array}$ & $\begin{array}{c}\text { Shanmugasundaram } \\
\text { Rajamani }^{4}(\%)\end{array}$ \\
\hline SIADH & $28 \%$ & $20.6 \%$ \\
\hline Drugs & $15 \%$ & $48.2 \%$ \\
\hline Renal disease & $12 \%$ & $13,4 \%$ \\
\hline Cardiac disese & $6 \%$ & $13.4 \%$ \\
\hline Liver disease & $2 \%$ & $1.7 \%$ \\
\hline Dehdration & $12 \%$ & $3 \%$ \\
\hline
\end{tabular}

\section{Conclusion}

Electrolyte abnormality was common in elderly patients, specialy Hyponatremia was the commonest electrolyte abnormality among hospitalised elderly patients admitted to medical wards. It is important to diagnose early to prevent mortality, morbidity, prolonged hospital stay and economic burden to the family and nation. Most of the patients had pre existing disease like DM, HTN. CKD. These patients were taking thiazide and other anti hypertensive drugs. This may be most important cause for hyponatremia in elderly patients and it is very important to advice regular electrolyte estimataion and to explain about common symptoms of hyponatremia to the patients, so that they can conult doctor early.

\section{References}

1. David B Mount,Fluid and electrolyte disturbance. Harrisons principle of internal medicine;2015;63:19:295-312.

2. Gary L Robertson, Disorders of the Neurohypophysis. Harrisons principle of internal medicine; 2015 ;404 :19: 22742283.

3. Alan $G$ Robinson,Joseph $G$ Verbalis. Posterior Pituitary. Williams Endocrinology; 2011;10:12:291-317.
4. Shanmugasundaram Rajamani et al, Clinico-etiological profile of Hyponatremia in elderly. International Journal of Medical and Health Research: 2017:3(7):25-30.

5. Soni Kumar et al. Serum sodium abnormality profile in hospitalized elderly patients in a tertiary care centre from north India: a cross sectional observational study. International Journal of Research in Medical Sciences:2018:6(1):321-327.

6. Nuket Bayram Kayar et al.Evaluation of the frequency of hyponatremia and risk factors among hospitalized geriatric patients. Biomedical Research: 2016:27(1):257-262.

7. Shivaji Patil et al. Incidence of Hyponatremia in Critically Ill Patients in Intensive Care Unit: Observational Study. International Journal of Dental and Medical Specialty:2016:3(1):12-15.

8. Sandar win et al.Current Trends in Prevalence and Etiologic Factors Responsible for Hyponatremia in Hospitalized Patients. Journal of Nephrology \& Therapeutics: 2016:6(6):2161-0959.

9. Verbalis JG, Goldsmith SR, Greenberg A, Schrier RW, Sterns RH. Hyponatremia treatment guidelines Am J Med. 2007;120:S1-21

10. Hawkins RC et al. Age and gender as risk factors for hyponatremia and hypernatremia Clinica Chimica Acta. 2003;337(1-2):169-72.

11. MY Rao, Sudhir U, Anil Kumar T, Saravanan S, Mahesh E, Punith K, et al. Hospital-Based Descriptive Study of Symptomatic Hyponatremia in Elderly Patients. JAPI. 2010;58:667-9.

12. Upadhyay A, Jaber BL, Madias NE. Incidence and prevalence of hyponatremia. Am J Med 2006; 119: 30-35. 
13. Smith MD, Mc Kenna K, Thompson JC. Hyponatremia. Clin Endocrinol 2000; 52: 667-678.

14. Waikar SS, Mount DB, Curhan GC. Mortality after Hospitalization with Mild, Moderate, and Severe Hyponatremia. Am J Med 2009; 122: 857-865.

15. Gosch M, Gstrein BJ, Heppner HJ, Lechleitner M. Hyponatremia in Geriatric In hospital Patients: Effects on Results of a Comprehensive Geriatric Assessment. Gerontology 2012; 58: 430-440. 